\title{
Extracellular Matrix and 3D printing
}

\author{
Jae-SeokEo ${ }^{1,2}$, Soo Hwa Jang1,2, Jong-Ock Shin ${ }^{1,2}$, Kyung-Hwan Jung ${ }^{3,4}$ and Nam-Soo Kim ${ }^{1,2}$ \\ ${ }^{1}$ Printing Nano Engineering lab, University of Texas at El Paso, USA \\ ${ }^{2}$ Department of Metallurgical, Materials and Biomedical Engineering, University of Texas at El Paso, USA \\ ${ }^{3}$ Gangwon Regional Division, Korea Institute of Industrial Technology, Korea \\ ${ }^{4}$ KIMM Metal 3D Printing Convergence Research Team, Korea
}

Submission: March 16, 2017; Published: March 27, 2017

"Corresponding author: Nam-Soo Kim, Department of Metallurgical, The University of Texas, Materials and Biomedical Engineering, The University of Texas at El Paso, USA, Tel: +1-915-747-7996; Fax: +1-915-747-8036; E-mail: nkim@utep.edu

\begin{abstract}
Extracellular matrix (ECM) is a non-cellular scaffold that surrounding cells to serve the various cell behaviorsincluding differentiation and migration. ECM is one of the promising biomaterial to be applied in various fields: tissue reconstruction, clinical application, and drug delivery system. While the ECM has been studied for more than 50 years, the material has not been fully verified for industrialization. By converging with three-dimensional (3D) printing technology,ECM can be ranked first favorable biomaterials in the regenerative medicine and commercialization of bio-printed ECM will be accelerated. Moreover, convergence of 3D printing and nano technology has brought up a new concept, biomimetic 3D structures. This even allowed 3D printing the ECM into a cactus structure of artificial bone, by controlling elastic modulus and porosity.
\end{abstract}

Keywords: Extracellular Matrix; 3D printing; Tissue engineering; Biomimetic 3D structures

\section{Opinion}

To overcome the current limitation of organ transplantation, there is no doubt about the importance of finding biomimic substitutes to restore of damaged tissues [1]. Extracellular matrix (ECM) is receiving great attention in regenerative tissue engineering field due to its high potential for application in human body. The composition and function of the ECM are dynamically remodeled depending on the location within the tissues, micro environments of neighboring cells, and physiological condition of the body [1-2]. The sophisticated interaction between ECM and cells initiated various cellular responses such as, growth, migration, development, even the structure and polarity of the cells [3]. Moreover, unlike other biomaterials like polymers, which may breakdown by hydrolysis, the ECM is highly biocompatible materials. It also can be leads the application for in vivo test [4-6].

Even though ECM has been studied a decade ago, it was difficult for ECM to be actually applied in human body, especially for reconstruction of damaged body parts. This was because it was unable to be placed accurately on the right location and the right environment, which is critical for biomedical application. Here, three-dimensional (3D) printing or additive manufacturing technology, which has become revolution in manufacturing industry and still evolving, can be converged with ECM in order to deal with these obstacles. 3D printing technology allows ECM to adjust its shape so that it fits perfectly to the damaged part of human body. Already many researchers have started to aim for manufacturing of 3D bio-scaffold. If scaffold like ECM can be 3Dprinted, it will definitely lead to another innovation in the industry [7].

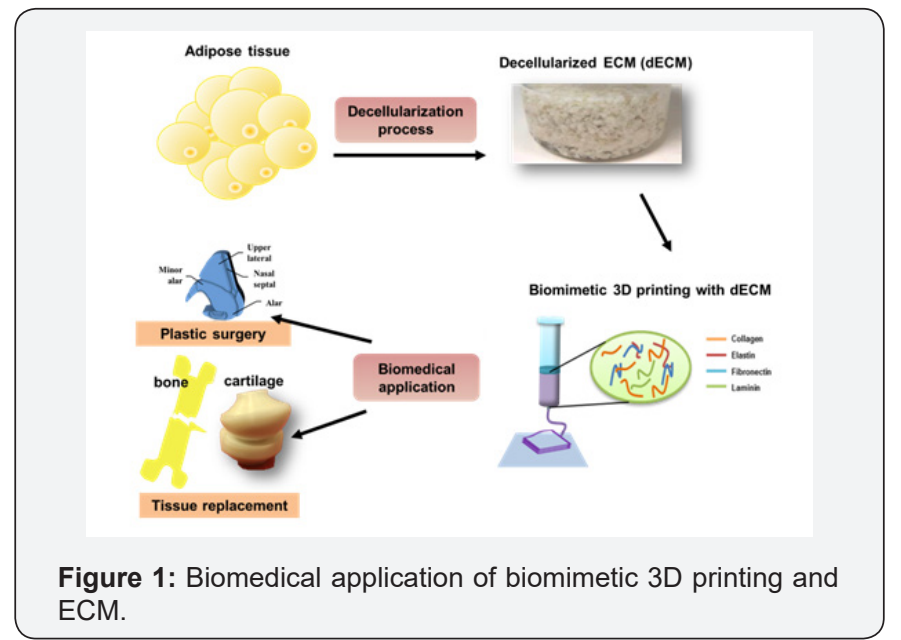

3D printed ECM can be further applied to reconstruction of bone fracture, cartilage, curing breast or un recovered heart damage, plastic surgery and creation of new drug delivery 
system (Figure 1). Especially, it is an outstanding prospect for manufacturing of artificial bone. 3D printing and nanotechnology have made ECM to shape a cactus 3D structure, which increases the surface area and thereby allowing more nutrition and water for artificial bone (Figure 2). Furthermore, 3D printed product showed great biocompatibility which allows in vivo application (Figure 3). Having able to control the elastic modulus and porosity, this biomimetic cactus structure will realize artificial bone with blood vessels.

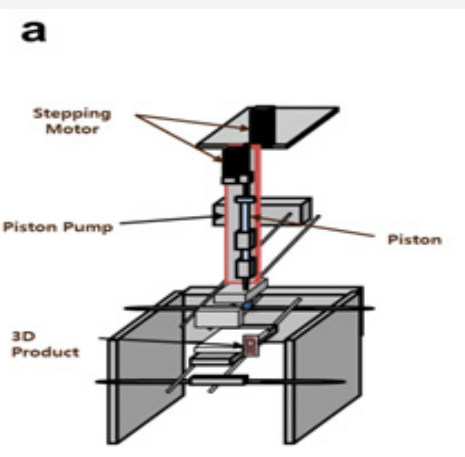

C

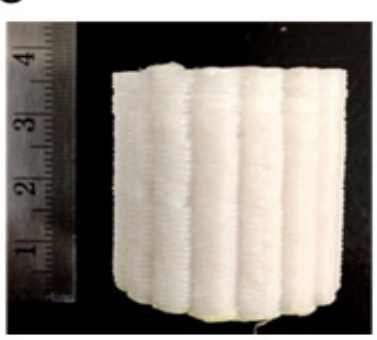

b

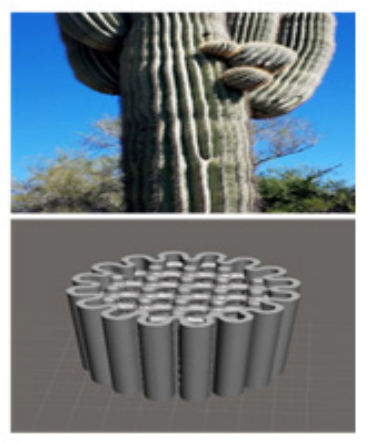

d

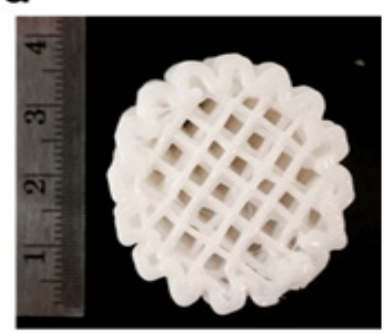

Figure 2: Biomimetic3D printing using cactus.

(a) Schematic diagram of Wall mounted 3D printer (Maker's Station).

(b) Formation of cactus (top), Design image for 3D printing using Rhinoceros 5 and Meshmixer software (bottom)

(c) 3D printed product (front side) and

(d) (Top Side).
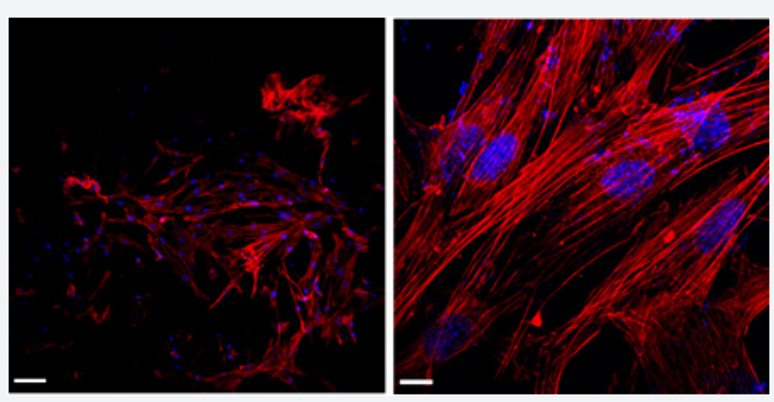

Figure 3: Highly biocompatible 3D printed product. C2C12 cells were grown and spread on the surface of 3D printed products.

The convergence of ECM and 3D printing technology can be the first step to an innovation in biomedical field. Once 3D printing complex bio-scaffold ECM and cell cultivation are successful, both 3D printing technology and ECM material can be a trend for biomedical applications, especially biomimetic 3D structures.

\section{Acknowledgment}

This research was supported by the National Research Council of Science \& Technology (NST) grant by the Korea government (MSIP) (CRC-15-03-KIMM). Thanks to Dr. Thomas Boland for allowing the use of biomedical laboratory to conduct research.

\section{References}

1. Dhakshinamoorthy Sundaramurthi, Sakandar Rauf and Charlotte A.E. Hauser (2016) 3D bioprinting technology for regeneratie medicine applications. IJB 2(2).

2. Martins-Green M, Bissel MF (1995) Cell-extracellular matrix interactions in development. Semin Dev Biol 6: 149-159.

3. Choi JS, Yang HJ, Kim BS, Kim JD, Kim YJ, et al. (2009) Human extracellular matrix (ECM) powders for injectable cell delivery and adipose tissue engineering. J of Controlled Release 139(2009): 2-7.

4. Brown BN, Freund JM (2011) Comparison of Three Methods for the Derivation of a Biologic Scaffold Composed of Adipose Tissue Extracellular Matrix. Tissue Engineering 17(4): 411-421.

5. O'Brien FJ (2011) Biomaterials \& scaffolds for tissue engineering. Materials today 14(3): 88-95.

6. Badyla SF (2002) The extracellular matrix as a scaffold for tissue reconstruction. Semin Cell Dev Biol 13(5): 377-383.

7. Pati F (2014) Printing three-dimensional tissue analogues with decellularizedextracellular matrix bioink. Nature Communications. 
This work is licensed under Creative Commons Attribution 4.0 License DOI: $10.19080 /$ CTBEB.2017.02.555596
Your next submission with Juniper Publishers will reach you the below assets

- Quality Editorial service

- Swift Peer Review

- Reprints availability

- E-prints Service

- Manuscript Podcast for convenient understanding

- Global attainment for your research

- Manuscript accessibility in different formats

( Pdf, E-pub, Full Text, Audio)

- Unceasing customer service

Track the below URL for one-step submission https://juniperpublishers.com/online-submission.php 